\title{
Determinants of nocturnal enuresis in homozygous sickle cell disease
}

\author{
D R J Readett, J Morris, G R Serjeant
}

\begin{abstract}
The determinants of nocturnal enuresis in homozygous sickle cell (SS) disease have been investigated in 16 enuretic and 16 age and sex matched non-enuretic children. Overnight fluid deprivation tests (8pm-8am) demonstrated no significant difference in maximum urine osmolality or urine volumes, although the latter tended to be higher in the enuretic children. Maximum functional bladder capacity, estimated by maximum voided volume during oral fluid loading, was lower and the ratio of overnight urine volume to maximum functional bladder capacity higher in the enuretic than the non-enuretic group. Enuretic children were more likely than nonenuretics to be considered deep sleepers by their family.

High urine volumes may contribute to nocturnal enuresis in SS disease, although the similar values in enuretic and non-enuretic children implies that additional factors determine the presence of enuresis. Low maximum functional bladder capacity, and a high ratio of overnight urine volume to maximum functional bladder capacity, appear to be important determinants.
\end{abstract}

The association between nocturnal enuresis and homozygous sickle cell (SS) disease has been attributed to poor urinary concentrating ability and obligatory high urinary volumes, ${ }^{1-4}$ although there is no experimental evidence to support this hypothesis.

A recent report from this unit documented a higher prevalence of nocturnal enuresis at age 8 years in children with SS disease than in control children with a normal haemoglobin (AA) genotype. ${ }^{5}$ In SS disease nocturnal enuresis was more common in children from large families but no consistent association could be demonstrated between enuresis and various measures of haematological and clinical severity.

In adults with SS disease the maximum urinary osmolality during fluid deprivation is fairly constant but in children it is variable and not clearly related to age. ${ }^{6}$ The present study sought to investigate the association of urinary concentrating ability and nocturnal enuresis in children with SS disease.

\section{Subjects and methods}

The subjects were selected from children enrolled in a cohort study of sickle cell disease set up by the Medical Research Council Laboratories at the University of the West Indies in
Kingston, Jamaica. Neonatal cord blood screening of 100000 consecutive normal deliveries at the local government maternity hospital between July 1973 and December 1981 identified 318 cases of SS disease, 201 case of sickle cell haemoglobin $\mathrm{C}$ (SC) disease, and 47 cases of the two types of sickle cell $\beta$ thalassaemia ${ }^{7}$ and these, along with 250 normal blood (AA genotype) controls, have been followed up from birth.

A questionnaire identified all children with SS disease who had been enuretic from birth and at the time of the study were enuretic nightly. The oldest eight boys and eight girls were selected from this group and matched by age and sex with 16 control children with SS disease all of whom had become dry at night before 4 years of age. The children were admitted to hospital for overnight study after informed consent had been obtained from their parents or guardians. At the time of the study they were all clinically in steady state, none having had significant illness for at least three weeks.

After physical examination and measurement of height and weight, blood was taken for determination of routine haematological variables, electrolytes, urea, creatinine, and plasma osmolality. From $8 \mathrm{pm}$ to $8 \mathrm{am}$, a fluid deprivation test was performed, without the use of exogenous antidiuretic hormone. The children were in bed from $10 \mathrm{pm}$ to 6 am during which urine was collected in enuretic boys by Paul's tubing, attached to a catheter bag allowing emptying after each voiding, and in enuretic girls by awakening every two hours. All urine samples were collected serially, the volume measured, and an aliquot deep frozen for later measurement of urine osmolality. Body weight was monitored throughout the study, more than 5\% loss being taken as an indication to abandon the test. At the end of the fluid deprivation test, blood samples were examined again for all indices measured at the start and the children were given breakfast and encouraged to drink freely.

Later the same morning maximum functional bladder capacity was estimated by measurement of maximum voided volume during diuresis induced by oral fluid loading. A minimum of 40 $\mathrm{ml} / \mathrm{kg}$ was taken orally by the children, the nature of the fluid depending upon personal choice (water, carbonated soda, juice, or syrup). After this they were encouraged to drink freely and during the ensuing diuresis instructed to wait as long as possible before emptying their bladder. All of the tests were conducted by one observer (DRJR) to ensure a similar degree of 
Table 1 Some haematological and biochemical indices in enuretic and non-enuretic children before and after fluid deprivation test. Results are mean (SD) and range

\begin{tabular}{|c|c|c|c|c|c|c|}
\hline & \multicolumn{2}{|c|}{ Enuretic $(n=15)^{*}$} & \multicolumn{2}{|c|}{ Non-enuretic $(n=16)$} & \multicolumn{2}{|c|}{ Significance } \\
\hline & Before & After & Before & After & $\begin{array}{l}\text { Before } \\
\left(p^{\prime}\right)\end{array}$ & $\begin{array}{l}\text { After } \\
\left(p^{2}\right)\end{array}$ \\
\hline Total haemoglobin $(\mathrm{g} / \mathrm{l})$ & $\begin{array}{l}76(6) \\
64-83\end{array}$ & $\begin{array}{l}78(7) \\
64-87\end{array}$ & $\begin{array}{l}73(10) \\
60-99\end{array}$ & $\begin{array}{l}75(9) \\
61-90\end{array}$ & $0 \cdot 2$ & 0.4 \\
\hline Fetal haemoglobin (\%) & $3 \cdot 7(2 \cdot 3)$ & $3 \cdot 8(2 \cdot 3)$ & $8 \cdot 0(5 \cdot 1)$ & $7 \cdot 4(4 \cdot 4)$ & $0 \cdot 06$ & 0.06 \\
\hline $\begin{array}{l}\text { Mean corpuscular haemoglobin } \\
\text { concentration }(g / l)\end{array}$ & $\begin{array}{l}0 \cdot 7-8 \cdot 3 \\
342(14) \\
310-370\end{array}$ & $\begin{array}{l}0 \cdot 6-8 \cdot 3 \\
343(18) \\
310-390\end{array}$ & $\begin{array}{l}1 \cdot 5-16 \cdot 5 \\
334(21) \\
200-370\end{array}$ & $\begin{array}{l}1 \cdot 3-13 \cdot 8 \\
324(18) \\
290-350\end{array}$ & $0 \cdot 3$ & 0.009 \\
\hline Reticulocytes (\%) & $\begin{array}{l}12 \cdot 2(4 \cdot 6) \\
4-23\end{array}$ & $\begin{array}{l}12 \cdot 8(4 \cdot 9) \\
5-25\end{array}$ & $12 \cdot 8(2 \cdot 7)$ & $\begin{array}{l}12 \cdot 0(3 \cdot 5) \\
4-18\end{array}$ & 0.5 & 0.6 \\
\hline Creatinine $(\mu \mathrm{mol} / \mathrm{l}) \dagger$ & $\begin{array}{l}59 \cdot 0(11 \cdot 6) \\
40-70\end{array}$ & $\begin{array}{l}61 \cdot 0(9 \cdot 0) \\
50-80\end{array}$ & $\begin{array}{l}54 \cdot 0(18 \cdot 4) \\
30-80\end{array}$ & $\begin{array}{l}61 \cdot 0(6 \cdot 4) \\
50-70\end{array}$ & 0.4 & $0 \cdot 8$ \\
\hline Urea $(\mathrm{mmol} / \mathrm{l})$ & $\begin{array}{l}2 \cdot 8(0 \cdot 7) \\
1 \cdot 2-3 \cdot 8\end{array}$ & $\begin{array}{l}2 \cdot 3(0 \cdot 9) \\
1 \cdot 0-4 \cdot 2\end{array}$ & $\begin{array}{l}3 \cdot 3(0 \cdot 8) \\
1 \cdot 6-5 \cdot 0\end{array}$ & $\begin{array}{l}2 \cdot 8(0 \cdot 7) \\
1.6-4 \cdot 2\end{array}$ & $0 \cdot 1$ & $0 \cdot 1$ \\
\hline
\end{tabular}

$\mathrm{p}^{1}$ refers to difference between pretest values, $\mathrm{p}^{2}$ to post test difference.

* One enuretic boy refused blood tests.

†Enuretic children, $n=13$; non-enuretic children, $n=12$.

'distress' before bladder emptying. At least two measurements were made for each child, the largest being taken as maximum functional bladder capacity.

Total haemoglobin concentration and red cell indices were measured on a Coulter S plus IV and fetal haemoglobin by alkali denaturation. ${ }^{8}$ Electrolytes were determined by a Technicon flame photometer, and urea and creatinine on a Technicon 6/60 sequential multiple analyser in the clinical chemistry laboratory of the University Hospital of the West Indies. Osmolality of the urine and of plasma was determined by freezing point depression in a Precision Systems Osmette A automatic osmometer. Height was measured by stadiometer and weight with a lever balance. Surface area was estimated from a standard nomogram. Parents were asked for their subjective assessment of the depth of sleep of the child.

The results in enuretic and non-enuretic children were compared by Wilcoxon's paired test and the $\chi^{2}$ test for trend. Association between variables was assessed by the product moment correlation coefficient.

\section{Results}

The ages of enuretic (mean 10.7 years, range $8 \cdot 7-13 \cdot 8)$ and non-enuretic $(10 \cdot 4$ years, 8.3-13.6) children were similar when assessed separately for boys and girls or for the sexes combined. Body surface area was similar in the two groups (enuretic children mean $1.03 \mathrm{~m}^{2}$, range $0 \cdot 83-1 \cdot 47$; non-enuretic children $1.05 \mathrm{~m}^{2}$, $0 \cdot 88-1 \cdot 40$ ). No appreciable sex differences were apparent in any of the results, which were therefore pooled for analysis.

Some haematological and biochemical data before and after fluid deprivation, are compared in table 1. Mean corpuscular haemoglobin concentration was similar in enuretic and nonenuretic children before but fell to significantly lower concentrations during fluid deprivation in the non-enuretic group. Fetal haemoglobin concentrations were higher in the non-enuretic group both before and after fluid deprivation. Creatinine concentrations were similar for the two groups before and after the test. Urea concentrations were higher in non-enuretic children after fluid deprivation but the trend toward higher concentrations before did not reach significance.

Maximum urine osmolality during fluid deprivation was similar for the two groups (table 2), although values varied considerably. Plasma osmolality did not differ between the groups either before or after fluid deprivation and increased by a similar extent in both enuretic and non-enuretic subjects.

The volume of urine (corrected for body surface area) passed overnight (10 pm-6 am) and during the 12 hour period of fluid deprivation ( $8 \mathrm{pm}-8 \mathrm{am}$ ) did not differ between the groups but enuretic children tended to have higher overnight urinary volumes (table 3 ). One enuretic child produced urinary volumes far in excess of the others but even after exclusion of his figures, the tendency toward higher overnight urine volumes in the enuretic group persisted. Body weight lost during the test reflected 12

Table 2 Maximum urine osmolality and plasma osmolality in enuretic and non-enuretic children before and after fluid deprivation test. Results are mean $(S D)$ and range

\begin{tabular}{llll}
\hline & Enuretic & Non-enuretic & $\begin{array}{l}\text { Significance } \\
(p \text { value })\end{array}$ \\
\hline Maximum urine & $433 \cdot 0(44 \cdot 5)$ & $439 \cdot 0(57 \cdot 4)$ & $0 \cdot 6$ \\
$\quad$ osmolality (mmol/l) & $371-554$ & $346-583$ & \\
Plasma osmolality: & $279 \cdot 0(10 \cdot 0)$ & $279 \cdot 0(9 \cdot 8)$ & $0 \cdot 9$ \\
$\quad$ before (mmol/l) & $261-290$ & $255-290$ & \\
Plasma osmolality: & $288 \cdot 0(9 \cdot 3)$ & $286 \cdot 0(8 \cdot 4)$ & $0 \cdot 8$ \\
after (mmol/l) & $276-304$ & $275-310$ & \\
\hline
\end{tabular}

Table 3 Urine volumes, maximum functional bladder capacity, and ratio of overnight urine volume to bladder capacity in enuretic and non-enuretic children. Results are mean $(S D)$ and range

\begin{tabular}{|c|c|c|c|}
\hline & Enuretic & Non-enuretic & $\begin{array}{l}\text { Significance } \\
(p \text { value })\end{array}$ \\
\hline $\begin{array}{l}\text { Overnight urine } \\
\text { volume }\left(\mathrm{ml} / \mathrm{m}^{2}\right)^{*}\end{array}$ & $\begin{array}{l}396(180) \\
215-925\end{array}$ & $\begin{array}{l}288(72) \\
174-394\end{array}$ & 0.09 \\
\hline$\ddagger$ & $\begin{array}{l}352(89) \\
215-484\end{array}$ & & $\begin{array}{l}0 \cdot 2 \\
0 \cdot 2\end{array}$ \\
\hline $\begin{array}{l}\text { Total urine } \\
\text { volume }\left(\mathrm{ml} / \mathrm{m}^{2}\right) \dagger\end{array}$ & $\begin{array}{l}602(245) \\
363-1240\end{array}$ & $\begin{array}{l}502(164) \\
275-853\end{array}$ & 0.3 \\
\hline & $\begin{array}{l}545(148) \\
363-783\end{array}$ & & 0.6 \\
\hline $\begin{array}{l}\text { Bladder capacity } \\
\left(\mathrm{ml} / \mathrm{m}^{2}\right)\end{array}$ & $\begin{array}{l}291(92 \cdot 8) \\
153-557\end{array}$ & $\begin{array}{l}395(109 \cdot 3) \\
259-657\end{array}$ & 0.005 \\
\hline $\begin{array}{l}\text { Overnight urine } \\
\text { volume divided by } \\
\text { bladder capacity }\end{array}$ & $\begin{array}{l}1.57(1 \cdot 37) \\
0.67-6.0\end{array}$ & $\begin{array}{l}0 \cdot 74(0 \cdot 22) \\
0 \cdot 43-1 \cdot 28\end{array}$ & 0.015 \\
\hline
\end{tabular}

"Data based on 13 enuretic and 14 non-enuretic children, and on $\dagger 12$ enuretic and 13 non-enuretic children because of incomplete urine collections.

¥Values excluding one child with extremely high urine volumes (see text) 


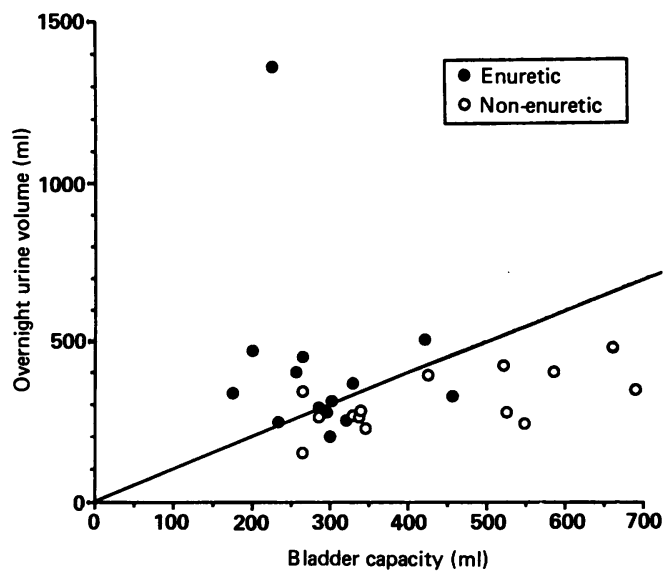

Figure 1 Association between overnight urine volume and bladder capacity in enuretic and non-enuretic subjects. Line represents ratio of overnight urine volume/bladder capacity $=1$ ( see text).

hour urinary volumes, and exceeded $5 \%$ in only one child. This was at the final weighing and it was not necessary to abandon the test. Maximum functional bladder capacity (corrected for body surface area) was lower, and the ratio of overnight urine volume to bladder capacity higher, in enuretic children (table 3, fig 1). The overall correlation between maximum bladder capacity and overnight urine volume was poor $(r=0.25, p=0.2)$ but was better for the non-enuretic $(r=0.62, p=0.04)$ than the enuretic even excluding the one child with excessive urinary volumes $(r=0.04, p=0.9)$.

In a subjective assessment by their families enuretic children were more likely to be deep sleepers $\left(\chi^{2}\right.$ test for trend, $\left.p=0 \cdot 01\right)$.

\section{Discussion}

The present study refutes the hypothesis that nocturnal enuresis in SS disease simply reflects a more severe defect in urinary concentrating ability with higher urinary volumes, as maximum urine osmolality and urinary volumes during fluid deprivation were similar for enuretic and non-enuretic children. The tendency toward higher overnight urine volumes in enuretic children is difficult to evaluate because maximum urine osmolality and 12 hour urine volumes were similar in the two groups. It could reflect higher fluid intake before the test or an abnormality of the circadian rhythm of urinary volume, but further study would be necessary to clarify this.

The observed differences in haematological and biochemical variables are of questionable significance. The higher urea concentrations after fluid deprivation in non-enuretic children are unlikely to reflect true variation in renal function because no difference occurred in creatinine concentrations, maximum urine osmolality, or urine volumes with fluid deprivation.

The association of enuresis with low concentrations of fetal haemoglobin both before and after and with high mean corpuscular haemoglobin concentration after fluid deprivation is interesting. Both low fetal haemoglobin and high mean corpuscular haemoglobin concentra- tions theoretically enhance sickling and might cause more severe damage to the vasa rectae system of the renal medulla and more profound hyposthenuria. The weakness of the association with fetal haemoglobin and the lack of an association between enuresis and lower maximum urine osmolalities with fluid deprivation, however, casts doubt on this suggestion. Moreover, the higher mean corpuscular haemoglobin concentration in enuretic children after fluid deprivation resulted from it falling in the non-enuretic children rather than a rise in the enuretic group.

The enuretic children had lower maximum functional bladder capacities and higher ratios of overnight urine volume to bladder capacity. A ratio of 1 implies that the entire overnight urine volume may be accommodated within the bladder and it is of interest that this ratio was exceeded in 10 out of 14 in the enuretic group but in only one out of 14 in the non-enuretic group. With ratios exceeding 1 , nocturnal urinary continence requires the child to inhibit bladder emptying during sleep, and also to get up during the night to urinate. Delay in attaining continence and hence a higher prevalence of nocturnal enuresis at a given age might therefore be expected.

A recent study from Denmark, on highly selected, severely enuretic patients without sickle cell disease, reported that overnight urine volume exceeded maximum bladder capacity in all subjects, although bladder capacity did not differ between enuretic and non-enuretic subjects. ${ }^{9}$ Other reports of maximum bladder capacity in enuretic and non-enuretic children without sickle cell disease have produced conflicting results depending upon the methodology. Maximum voided volumes have indicated smaller bladder capacities in enuretic subjects, ${ }^{10}{ }^{11}$ but direct measurements under anaesthesia found no difference. ${ }^{11}$ It is for this reason that we have used the term maximum functional, not anatomical, bladder capacity.

Depth of sleep has been reported as a determinant of enuresis in children without sickle cell disease ${ }^{12}$ and a similar relationship was apparent in children with SS disease in the present study, although the highly subjective method of assessment does not allow firm conclusions.

The aetiology of nocturnal enuresis in normal children is probably complex and multifactorial (fig 2) with the common end point of inability to

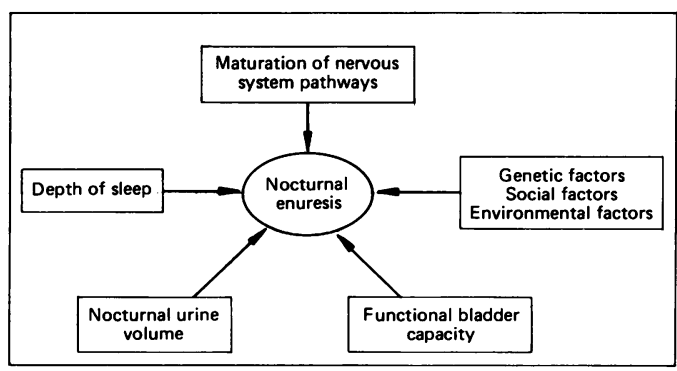

Figure 2 Proposed scheme of factors relevant to nocturnal enuresis. 
inhibit bladder emptying during sleep. In SS disease a high nocturnal urinary volume may be important but affects all SS children, implying that other factors are important in exceeding the enuretic threshold. These factors include a small bladder capacity, a high ratio of overnight urine volume to bladder capacity and possibly subjectively deep sleep. Previous studies have shown nocturnal enuresis in SS disease and in normal children is more common in boys, in children from large families, and in those with a family history of enuresis. ${ }^{5}{ }^{13-15}$ These observations, plus the finding that nocturia in nonenuretic children and adults with SS disease is more common than in normal controls, ${ }^{1-3}$ are consistent with a hypothesis that a variety of factors in SS disease combine to exceed an enuretic threshold.

The major implication of these findings relates to treatment, which should aim to convert enuresis in SS disease, into nocturia. Pharmacological treatment with exogenous antidiuretic hormone is inappropriate as the high nocturnal urinary volumes are not thought to be caused by inadequate concentrations of antidiuretic hormone. Tricyclic antidepressants, though possibly having a place in short term treatment, are unlikely to produce long term cure. Enuresis alarms, which aim to condition the child to awake and empty the bladder rather than wetting the bed, are the most logical form of treatment and their effectiveness should be investigated in children with homozygous sickle cell disease.
We thank Dr Michael Golden and the staff of the Tropical Metabolism Research Unit for their inpatient facilities and Dr Terrence Forrester for the use of the osmometer.

1 Suster G, Oski FA. Enuresis in sickle cell anemia. Am $\mathcal{f}$ Dis Child 1967;113:311.

Noll JB, Newman AJ, Gross S. Enuresis and nocturia in sickle cell disease. $\mathcal{F}$ Pediatr 1967;70:965-7.

3 Kwak KJ, Scott RB, Ferguson AD. Studies in sickle cell anemia XXXIV. Observations on enuresis in children and nocturia in adults. Clin Pediatr (Phila) 1969;8:344-6.

4 Akinyanju O, Agbato O, Ogunmekan AO, Okoye JN. Enuresis in sickle cell disease. 1. Prevalence studies. 7 Trop Enuresis in sickle cell

5 Readett DRJ, Morris JS, Serjeant GR. Nocturnal enuresis in sickle cell haemoglobinopathies. Arch Dis Child 1990;65: 290-3.

6 Statius van Eps LW, Schouten H, Ter Haar Romeny Wachter CCH, La Porte-Wijsman LW. The relation between age and renal concentrating capacity in sickle cell disease and haemoglobin C disease. Clin Chim Acta 1970 27:501-11.

7 Serjeant GR, Serieant BE, Forbes M, Hayes RJ, Higgs DR, Lehmann $H$. Haemoglobin gene frequencies in the Jamaican population: a study in 100000 newborns. $\mathrm{Br}$ J Haematol 1986;64:253-62.

8 Betke K, Marti HR, Schlicht I. Estimation of small percentages of fetal haemoglobin. Nature 1959;184:1877-8. 9 Nørgaard JP, Rittig S, Diurhuus JC. Nocturnal enuresis: an approach to treatment based on pathogenesis. $\mathcal{F}$ Pediat approach to treatment

10 Zaleski A, Gerrard JW, Shokeir MH. Nocturnal enuresis: the importance of a small bladder capacity. In: Kolvin I MacKeith RC, Meadow SR, eds. Bladder control and enuresis. London: Heinemann, 1973:95-101.

11 Starfield B. Functional bladder capacity in enuretic and non enuretic children. $\mathcal{f}$ Pediatr 1967;70:777-81.

12 Graham P. Depth of sleep and enuresis: a critical review. In Kolvin I, MacKeith RC, Meadow SR, eds. Bladder contro and enuresis. London: Heinemann, 1973:78-83.

13 de Jonge GA. Epidemiology of enuresis: a survey of the literature. In: Kolvin I, MacKeith RC, Meadow SR, eds. Bladder control and enuresis. London: Heinemann, 1973 39-46.

14 Jarvelin MR, Vikevainen-Tervonen L, Moilanen I, et al. Enuresis in seven-year-old children. Acta Paediatr Scand 1988;77:148-53.

15 Golding J, Tissier G. Soiling and wetting. In: Butler NR, Golding J, eds. From birth to five. Oxford Pergamon Press, Golding J, eds. 